\title{
Japanese Teaching Mode Innovation on the Background of Big Data
}

\author{
Fangting Liu \\ College of Foreign Languages, Bohai University, Jinzhou, 121013, China \\ 261146357@qq.com
}

Keywords: big data; Japanese teaching; learning analysis model; foreign language learning model; teaching mode innovation

\begin{abstract}
Big data technology describes a new era of technology and system, through high-speed from the large-scale diversified data capture, the value of the detection and analysis technique to extract data. Big data to the education has brought new opportunities and challenges, Japanese language teaching must also adapt to the request of the era of big data. In this paper, based on the basic characteristics of the era of big data, combined with the basic requirements of college Japanese teaching reform, research study under the background of big data analysis model and the foreign language learning model, puts forward the big data under the background of Japanese teaching mode innovation strategy, including: set up the big data under the background of Japanese education concept, implementing big data under the background of Japanese teaching strategy, create under the background of big data in Japanese teaching environment, perfecting the big data under the background of Japanese teaching evaluation.
\end{abstract}

\section{Introduction}

Big data is not only means that the large capacity of data, but also embodied in the difference in "big data" and the characteristics of the "very large data". Big data refers to the capacity of the data, data acquisition speed or said, limiting the use of traditional relation method on the analysis of the data processing ability, need to use the horizontal extension mechanism in order to improve processing efficiency. Big data technology describes a new era of technology and system, through high-speed from the large-scale diversified data capture, the value of the detection and analysis technique to extract data [1]. Compared with traditional data, people will be the characteristics of the large data is summarized as $5 \mathrm{~V}$, the large size (Volume), high speed (Velocity), the modal (Variety), more difficult to identify, Veracity and Value of large low density (Value).Big data changed education, Japanese language teaching must also adapt to this change. In this paper, we study the big data under the background of teaching mode innovation, to provide Japanese teaching operational strategies and methods.

\section{Learning Analysis Model on the Background of Big Data}

Learning Analytics is in recent years the rapid development of the new hot spot in the field of education technology, application of advanced analysis methods and tools to predict problems arising in the course of Learning results, diagnostic collection technology, optimizing the study effect of teaching. Although the traditional teaching process also the evaluation of student achievement and analysis of the teaching process, in order to improve the quality of teaching, but these activities in the acquisition of data is very limited, Informatization level is not high, and the results of the analysis for the long cycle of intervention in the teaching, the effect is poorer. As teaching is becoming more and more network resources, as well as the popularity of web-based learning style, learning behavior and learning result data is also available in more rich. It's for learning analysis technology and application laid the material foundation of, and puts forward the urgent demand, into people's vision and develop rapidly.

Learn loosely combined analysis of a series of data collection tools and analysis technology, the study of the students' investment situation, performance, and the study progress, in order to timely amend the results for curriculum, teaching and assessment. Study analysis has the following 
characteristics: (1) A variety of data sources, most used in the analysis of the data from the learning management system, content management systems, and the student archives, etc., there are some informal knowledge management system or from the student individual digital learning materials; (2) the modern analysis method, data processing, mining and analysis, the difference between traditional evaluation model and evaluation method of teaching. Data analysis process automation, and can according to the demand for real-time feedback analysis results; (3) providing visual analysis, intuitively display data, facilitate students and teachers to judge oneself circumstance; (4) geared to the needs of teachers and students, learning direct service object is the analysis of the teachers and students, in the process of learning in a variety of data to provide analysis and recommendations, based on the study of feedback to help teachers improve teaching quality and teaching level, and professional skills, help students improve the quality of learning and learning results.

Learn technology is based on the analysis of teaching related data collection, through the analysis and calculation, according to the individual differences of personalized adjustment, improve the learning performance. Learn analysis model is studied by analyzing system, process, things or concept of a form of expression. Based on the analysis of large data learning model is shown in Fig. 1 [2].

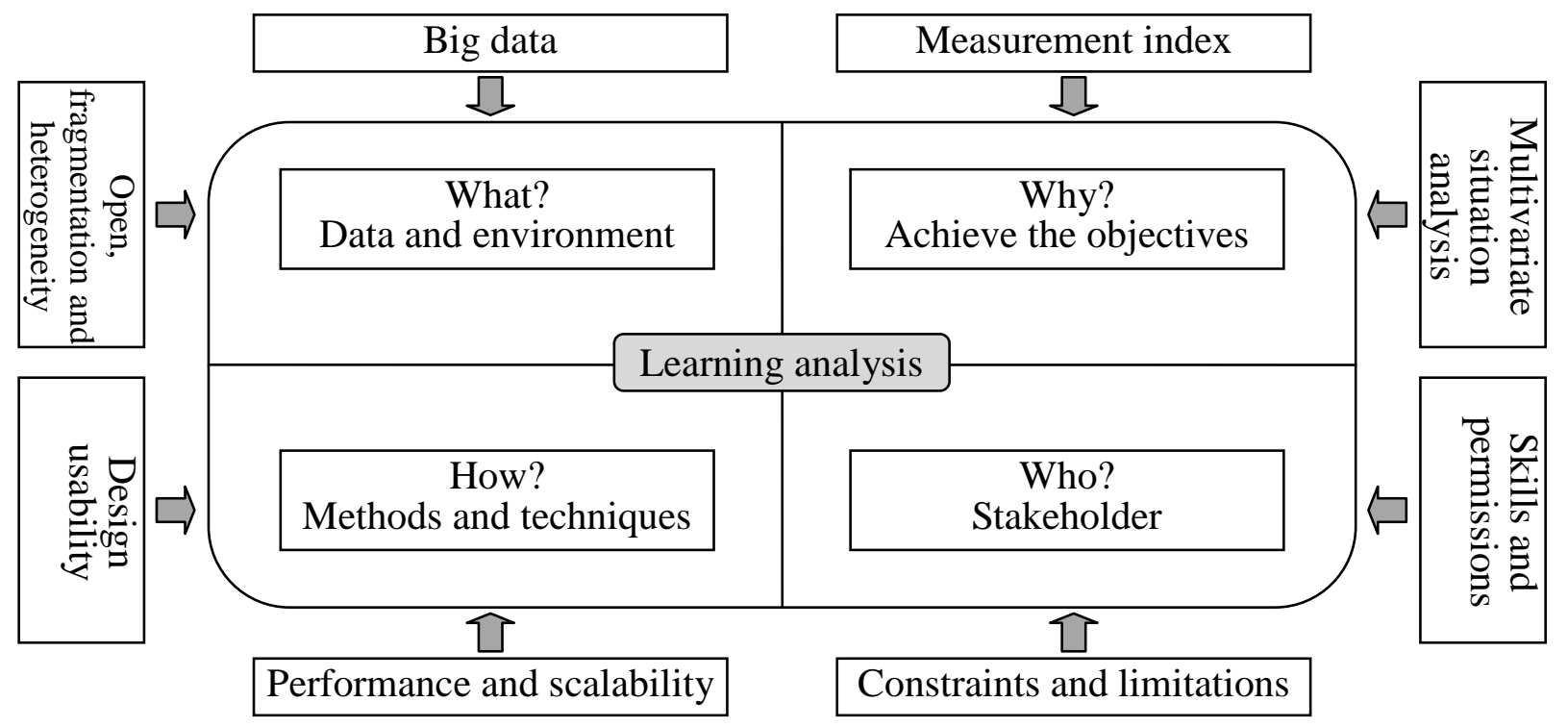

Fig. 1. Learning analysis model based on big data

\section{Foreign Language Learning Model on the Background of Big Data}

To study under the background of big data analysis model as the foundation, under the background of big data model of foreign language learning consists of two guide inner loop and outer loop, as shown in Fig. 2. To quantify and wisdom of foreign language teaching innovation provide clear conceptual framework and cognitive premise.

Inner loop is also called the guiding layer, by clear objectives, assessment requirements, design, assessment, optimization proposal, monitoring, evaluation, analysis, reflection and monitor intervention, and etc. among them, the clear goal, the teaching goal is to point to the direction of the teaching activities and anticipated results, is the starting point and ultimate end-result of all teaching activities, both associated with the purpose of education and training objectives, and is different from the purpose of education and training objectives; Assessment needs to foreign language teaching program, teaching outline and teaching guidance, on the basis of analysis of the practical need of unit of choose and employ persons to graduate from foreign language, combining with the characteristics of the students' level and demand for foreign language teaching assessment; Design review, mainly design estimation index system, index sign is the overall goals of specific measure system, using a single indexes have one-sidedness and subjectivity, building composed of multiple 
indicators scientific and reasonable evaluation index system is essential for the science fair assessment results; Optimization recommendations, using the scientific method, the domain experts to design the evaluation index system of optimizing Suggestions, make it more in line with the requirements of foreign language training objectives; Monitoring assessment, including two process monitoring and evaluation, monitoring is based on the evaluation index to monitor the teaching process, and evaluation is to follow the assessment criteria to evaluate foreign language teaching process and results; Analysis of reflection, based on monitoring evaluation results, the foreign language teaching process and the results are in-depth analysis, sum up experience from them; Monitoring and intervention, according to the result of reflection, intervention strategies for implementation of the related in the process of monitoring, to improve the effect of foreign language teaching.

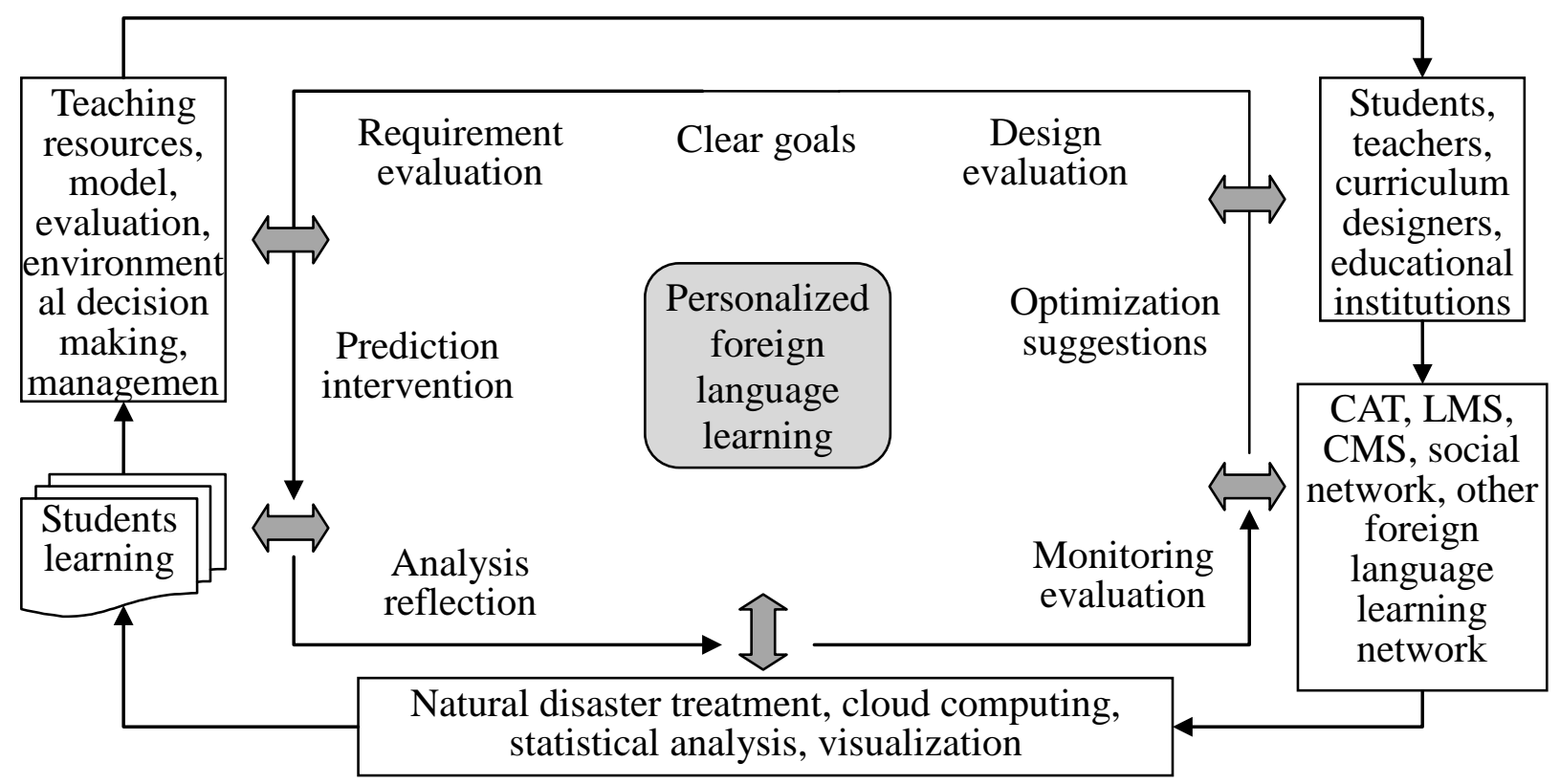

Fig. 2. Foreign language learning model based on big data

Outer loop also calls the operational layer, inner loop circulation influence abroad. Student learning as the starting point, External loop the teaching has management, stakeholders, data source and the information technology and so on four parts. (1) The teaching management, including teaching resources, patterns, teaching evaluation and environmental decision making and management strategy, effective development of teaching resources for teaching material and can be provided by the use of conditions, teaching mode is based on certain teaching theory and set up a relatively stable teaching activity framework and procedure, teaching evaluation is a reality in teaching activities, or potential value judgment, the process of environmental policymaking is related to the big data background of teaching environment information for decision-making, management strategy is the management process of foreign language teaching methods and means of collection; (2) Stakeholders, including students, teachers, intelligent tutor and education institutions, etc. For students, consider is the organizational learning, need to protect user information at the same time, to prevent data be abused, pay attention to privacy and ethical questions; For teachers, adjust teaching strategies according to learners' information, to intervene; For intelligent tutor, according to the characters of learners, such as learning styles, interests, preferences, knowledge level, personalized recommendation learning resources, learning path; For education institutions, analyze the potential risk warning and intervention of students, improve students' test scores and graduation rates. (3) Data source, under the background of big data resource of foreign language learning has a very wide range of data sources, including CAT, LMS, CMS, and so on many social networks and other foreign language learning network. Data formats including structured data and unstructured data, and structured data are stored in a database, and implementation can be expressed in a two-dimensional table structure to logical data. 
Two-dimensional unstructured data is not convenient to use database logical table, including all the office document formats, text and pictures, a subset of the set of standard generalized markup language XML, HTML, all kinds of statements, image and audio/video information, etc.; (4) Information technology is used to manage and process information in a variety of technology, information technology development for the big data age (C)reated the conditions, including natural disaster treatment, cloud computing, such as statistical analysis, and visualization.

\section{Japanese Teaching Mode Innovation on the Background of Big Data}

Previous research achievements for reference [3], combined with the authors years of teaching experience, Japanese is proposed under the background of big data in Japanese teaching mode innovation mainly includes the following four aspects:

(1) Set up the big data under the background of Japanese education concept. Education idea, about the idea of education method, education the main body is formed in the teaching practice and education thinking activity of "education ought to be" rational knowledge and subjective requirements, including the education objective, education mission, ideal education purpose, education, education target, education requirements, the principle of education, etc. Big data under the background of Japanese education concept includes four aspects: first, using big data to standardization and unification pattern, form of diversification and individuation of Japanese education idea; Second, the use of big data to authority and solid state, to establish culture and dynamic mechanism of Japanese education; Third, the use of big data say goodbye to the simple empirical formula, speculative and top-down teaching mode, implement the empirical type, scientific type and bottom-up new classroom teaching mode; Fourth, the use of big data discard the traditional average education, implementation of education, the diversity of the real according to their aptitude; In a word, use big data this comprehensive tool, integration of the theory of multiple intelligence and Japanese learning style, implement differentiation, personalization and culture in foreign language teaching strategies, in order to obtain the maximum effective teaching.

(2) Under the background of big data of Japanese teaching strategy. Teaching strategies are made to achieve the teaching goal, into the teaching process of implementation of overall plan, organize the teaching process, including reasonable selection of specific teaching methods and materials, to make teachers and students teaching behavior process. Big data under the background of Japanese teaching strategy includes three aspects: first, make full use of the flip longed for classes and class implements the integration of online and offline way of Japanese teaching. Big data sparked longed for class was born, and based on big data for class and brings challenges and opportunities to the development of foreign language teaching. Big data prompted the diversification of teaching resources and means, greatly challenges the traditional classroom teaching, turning the classroom as with the innovation of teaching mode widely used in foreign language teaching; Second, integrating the Japanese traditional classroom teaching method, make the Japanese teaching strategies of the era of large data. Teachers help students analyze the suitable learning methods and strategies, communication and inspire thinking as the core, improve the students' listening, speaking, reading, writing, translating and thinking ability, adaptive learning for students, for learning and corrective learning organization and management ability; Third, teachers should strengthen the study, paying attention to accumulation, learning to classification, for students to provide more learning resources, learning advice and evaluation mode. Big data era qualified Japanese teacher knowledge more widely, the stronger comprehensive ability, team cooperation consciousness is stronger.

(3) To create large data under the background of Japanese teaching environment. Teaching environment is a complex system composed of many different elements, generalized teaching environment refers to all conditions of the school teaching activities; Affect the special teaching environment refers to the classroom teaching of all the conditions, including class size, seat model, class atmosphere and the relationship between teachers and students, etc. On the teaching methods, teachers' higher learning Japanese website recommends screening value to students, students accept Japanese listening and reading and so on various aspects of information at any time. On the word memory, advocate students make use of the word memory software and network learning 
community. In teaching Japanese sentences using "sentence pattern, data collection and sorting, combining the text applied" of "backward thinking" pattern, weakening the teacher leading teaching method, let the students use search engines to get a lot of the sentence pattern data. In the writing teaching, the Internet in various writing system, can help teachers solve meets the requirement of students point-to-point problem; In Japanese language classroom teaching, teachers should take advantage of the characteristics of young students easy to accept mobile digital information, will be associated with the current politics hot spot, such as instant messaging, digital images and video clips design to teaching, help students accept fragmentation of knowledge information as much as possible.

(4) Improve the big data under the background of Japanese teaching evaluation. Big data can be more scientifically teaching evaluation. According to the trend of the development of the era of big data Japanese teaching, use of big data to improve the Japanese teaching evaluation system is feasible. On the one hand, to adjust traditional Japanese teaching evaluation system, change the examination as the main form of evaluation system, using big data to the Internet, the teaching effect in the teaching to implement dynamic and circulation. Not only teachers' teaching performance evaluation, but also students' study effect evaluation. The assessment content not only including reading and writing, also including the heard. Examination should also be in the form of diversification, assessment center of gravity from the reading and writing gradually shift to hear, and hear.

\section{Conclusion}

Big data era, university of Japanese innovation to promote the teaching efficiency of teaching and learning efficiency is improved, provides teachers' teaching research large capacity, diversification, fast speed and high value support data, at the same time effective continuously stimulate students' interest in learning [8]. In this paper, based on the basic characteristics of the era of big data, combined with the basic requirements of college Japanese teaching reform, the education of Japanese teaching reform era of big data analyzed the opportunities and challenges facing, and gives the corresponding countermeasures, in order to help the school improve the efficiency of Japanese teaching, enhance the students' application ability in Japanese.

\section{References}

[1] X. L. Li, H. G. Gong, "A survey on big data systems," Scientia Sinica Informationis, vol. 45, no. 1, pp. 1-44, 2015.

[2] Q. Jiang, W. Zhao, P. J. Wang, L. P. Wang, "On the teaching culture," China Educational Technology, vol. 37, no. 1, pp. 85-92, 2015.

[3] J. L. Chen, "MOOCs and Foreign Language Teaching Studies in the Big Data Era: Challenges and Opportunities," Technology Enhanced Foreign Language Education, vol. 37, no. 1, pp. 3-8, 2015.

[4] Z. K. Li, "Exploration of English Teachers' Educational Concept and Teaching Ability in Big Data Age," Teacher Education Forum, vol. 29, no. 3, pp. 32-36, 2016.

[5] H. Cui, "The New Notions and New Attempts of College English Teaching in the Big Data Era," Overseas English, vol. 19, no. 6, pp. 51-52, 2015.

[6] W. X. Huang, "The New Notions and New Attempts of College English Teaching in the Big Data Era," Contemporary Foreign Languages Studies, vol. 35, no. 7, pp. 53-57, 2015.

[7] P. P. Liu, The teaching of Japanese sentence patterns in the era of big data," The Science Education Article Collects, vol. 9, no. 3, pp. 176-177, 2015.

[8] M. Xie, Y. L. Lai, "On Innovative College English Teaching during the Age of Big Data Taking Flipped Classroom Learning Model For Example," Journal of Gannan Normal University, vol. 37, no. 2, pp. 87-90, 2016. 